\title{
Who purchases cigarettes from cheaper sources in China? Findings from the ITC China Survey
}

\author{
Tingting Yao, ${ }^{1,2}$ Jidong Huang, ${ }^{3}$ Hai-Yen Sung, ${ }^{1}$ Michael K Ong, ${ }^{4}$ Zhengzhong Mao, ${ }^{5}$ \\ Yuan Jiang, ${ }^{6}$ Geoffrey T Fong, ${ }^{7,8}$ Wendy Max ${ }^{1}$
}

Institute for Health \& Aging University of California, San Francisco, California, USA ${ }^{2}$ Center for Tobacco Control Research and Education, University of California, San Francisco, California, USA ${ }^{3}$ Health Policy Center, Institute for Health Research and Policy, University of Illinois at Chicago, Chicago, Illinois, USA ${ }^{4}$ Division of General Internal Medicine and Health Services Research, Department of Medicine, University of California, Los Angeles,

California, USA

${ }^{5}$ Huaxi School of Public Health Sichuan University, Chengdu, Sichuan, China

${ }^{6}$ National Tobacco Control Office, Chinese Center for Disease Control and Prevention, Beijing, China 7 Department of Psychology, University of Waterloo, Waterloo, Ontario, Canada ${ }^{8}$ Ontario Institute for Cancer Research, Toronto, Ontario, Canada

\section{Correspondence to}

Dr Tingting Yao, Institute for Health \& Aging, University of California, San Francisco, 3333 California Street, Suite 340, San Francisco, CA 94118, USA: tingting.yao@ucsf.edu

Received 6 March 2013 Revised 21 August 2013 Accepted 6 September 2013 Published Online First 27 September 2013

\section{ABSTRACT}

Objective The availability of cigarettes from cheaper sources constitutes a major challenge to public health throughout the world, including China, because it may counteract price-based tobacco control policies. The goal of this study was to identify factors associated with purchasing cigarettes from cheaper sources among adult smokers in China.

Methods Data were analysed from Waves 1 to 3 of the International Tobacco Control China Survey conducted in 2006-2009 among adult smokers in six cities in China ( $\mathrm{N}=7980)$. One survey question asked, "In the last 6 months, have you purchased cheaper cigarettes than you can get from local stores for economic reasons?" We examined whether sociodemographic factors and smoking intensity were associated with purchasing cigarettes from cheaper sources using the general estimating equations model. Sociodemographic factors considered were gender, age, marital status, monthly household income, education, employment status and city of residence.

Results $15.6 \%$ of smokers reported purchasing cigarettes from cheaper sources. After controlling for other covariates, the associations of the behaviour of purchasing cigarettes from cheaper sources with age (adjusted $O R(A O R)=1.49,95 \% \mathrm{Cl} 1.17$ to 3.92 for age 18-24 compared with age 55+) and with income ( $A O R=2.93,95 \% \mathrm{Cl} 2.27$ to 3.79 for low income compared with high income) were statistically significant, but there was no statistically significant relationship with smoking intensity.

Conclusions Our findings indicate that young and lowincome smokers are more likely than older and highincome smokers to purchase cigarettes from cheaper sources in China. Tobacco control policies that reduce the availability of cigarettes from cheaper sources could have an impact on reducing cigarette consumption among young and low-income smokers in China.

\section{INTRODUCTION}

China is the largest consumer of tobacco in the world, and smoking has a large impact on the population and health. In 2010, current smoking prevalence in China was 28.7\%: $52.9 \%$ for men and $2.4 \%$ for women. ${ }^{1}$ In addition, more than 556 million non-smoking adults $(61.8 \%)$ in China were exposed to secondhand smoke in 2010. ${ }^{2}$ The smoking prevalence in rural areas is higher than in urban areas $(30.0 \%$ vs $27.1 \%$, in 2012$) .{ }^{2}$ China is the largest tobacco producer in the world, with 2.4 trillion cigarettes produced in 2011. ${ }^{3}$ Smoking increases the risk of lung cancer, cardiovascular disease and other smoking-related diseases that result in premature death and higher medical expenditures in China. It is estimated that there are 1 million tobacco attributable deaths each year in China and this number is expected to rise to 2.2 million per year by $2020 .{ }^{4} 5$ A recent study found that the total healthcare expenditures attributable to cigarette smoking in China rose by $154 \%$ from 2000 to 2008 , amounting to $\$ 6.2$ billion in 2008 . $^{6}$

Cigarette smoking is an important public health issue in China. In order to reduce smoking prevalence, it is necessary to understand cigarette purchasing behaviour. Multiple studies worldwide have shown that increasing cigarette prices is one of the most effective ways to reduce cigarette consumption. A comparison of trends in cigarette prices and overall US cigarette consumption from 1970 to 2007 shows that there is a strong correlation between high prices and low consumption even in the context of many other factors that influence consumption. ${ }^{7}$ A study conducted in Turkey found that a 20\% increase in the Special Consumption Tax on tobacco in January 2010 resulted in a $13.6 \%$ decrease in tobacco consumption. ${ }^{8}$ A recent review that assessed 100 studies on tobacco taxes, including a growing number from low-income and middle-income countries, demonstrated that increases in tobacco taxes are a highly effective strategy for reducing tobacco use. ${ }^{9}$

Previous studies suggest that the presence of cigarettes from cheaper sources (eg, internet and discount cigarettes) may undermine the effects of price and tax policies on reducing smoking prevalence and cigarette consumption. When cigarette prices go up, besides quitting and cutting back their cigarette consumption, some smokers may switch to buying cheaper brands of cigarettes or cigarettes from cheaper sources to save money. Several studies conducted in developed countries showed that in response to high cigarette taxes, $34-61 \%$ of smokers chose to buy cigarettes from cheaper sources to save money on cigarettes. ${ }^{10}{ }^{11} \mathrm{~A}$ study conducted in New Jersey found that when the cigarette tax increased between 2000 and 2002, among current cigarette smokers, the prevalence of ever purchasing tobacco via the internet increased by over $500 \%$ and usually purchasing cigarettes via the internet increased by nearly $300 \% .^{12} \mathrm{~A}$ recent study from the US Minnesota Adult Tobacco Survey Cohort Study found that 53\% of the participants reported buying cigarettes from less expensive places in response to increasing prices. ${ }^{13}$ However, little research has focused on this issue in China. China's tobacco industry is both owned and regulated by the government. The Chinese government plays an important role in both tobacco and cigarette production through the State Tobacco 
Monopoly Administration (STMA) and the China National Tobacco Company (CNTC). The STMA forms part of the same organisation as the CNTC, but works as a governmental body for administration of the tobacco monopoly. The STMA determines government tobacco policy, including the allocation of tobacco production quotas among the provinces, pricing of tobacco leaf, production of cigarettes and international trade parameters. Since 1991, the STMA has delegated authority to the CNTC for the administration of all aspects of tobacco policy. ${ }^{14}$ The CNTC produces more than 200 domestic cigarette brands. ${ }^{15}$ Unlike other countries, in China there is huge price variation among brands, ranging from less than US\$1 per pack to more than US $\$ 30$ per pack. A previous study by Li et al examined the purchase of cheaper cigarettes among smokers in six cities in China and found that the lowest tertile (lower bound) of cigarette prices paid by them ranged from US $\$ 0.41$ per pack in Shenyang to US\$1.08 per pack in Shanghai. They also found that smokers who reported buying the cheapest cigarettes tended to be older, heavier smokers and to have lower education and income. ${ }^{16}$ Cigarettes are also available from cheaper sources in China. However, to our knowledge, no study has examined the purchase of cigarettes from cheaper sources in China. Given that China has the largest number of smokers (350 million smokers) in the world, ${ }^{1}$ it is important to investigate the extent of purchasing cigarettes from cheaper sources and how that behaviour impacts the effects of price and tax policies on reducing cigarette smoking among Chinese smokers. The objective of this study was to determine the prevalence and characteristics of smokers who purchase cigarettes from cheaper sources in China.

\section{METHODS}

\section{Data source}

We analysed data from the International Tobacco Control (ITC) China Survey. The ITC Project is the first international cohort study of tobacco use consisting of parallel longitudinal cohort surveys of tobacco users in 22 countries so far and non-users in most of those countries. The ITC China Survey is a longitudinal survey of smoking behaviour among adults in seven cities in China: Beijing, Shanghai, Guangzhou, Changsha, Kunming, Shenyang and Yinchuan. These seven cities were selected because they differ in size, geographic location and level of economic development. The ITC China Survey collects detailed information about demographic characteristics, smoking behaviours, cigarette purchasing behaviours and smoking cessation. Four waves of the ITC China Survey have been conducted by team members from the central and local offices of the China Center for Disease Control and Prevention (CDC) in 2006, 2007/2008, 2009 and 2011.

\section{Study design and sample}

Eligible respondents in each city included current adult smokers and non-smokers 18 years of age and older. In each city, the ITC China Survey employed a multistage cluster sampling design to create a representative cohort of adult urban current smokers and non-smokers. Current smokers were defined as having smoked 100 cigarettes in their lifetime and currently smoking at least once a week. Using a standardised questionnaire, a face-to-face interview was conducted to collect demographic characteristics and detailed information on smoking history from each respondent.

Our study sample focused on current smokers who were interviewed in each of the first three waves of the ITC China Survey from all cities except for Kunming, as it was added to the ITC China Survey at Wave 3. We focused on current smokers because the study question focused on the purchasing behaviour of those who currently smoke. We did not use the Wave 4 data because the data set was not yet available when we conducted this study.

Among the six-city study sample, 2773 respondents (8319 observations) were classified as current smokers in all three waves, and 338 respondents (539 observations) switched smoking status during the three waves. As a result, a total of 8858 observations of current smokers were eligible for the final study sample. After excluding 240 observations with missing values for purchasing cigarettes from cheaper sources and 638 additional observations with missing values for demographic characteristics or smoking intensity, a total of 7980 observations were included in the final study sample.

All materials and procedures used in the ITC China Survey were reviewed and cleared with regard to ethics by the Office of Research Ethics Board at the University of Waterloo (Waterloo, Canada) and the Institutional Review Boards at Roswell Park Cancer Institute (Buffalo, USA), the Cancer Council Victoria (Victoria, Australia) and the China CDC (Beijing, China). A detailed description of the survey methods can be found elsewhere. ${ }^{17}$

\section{Measures}

Dependent variable

The dependent variable was obtained by the response to the question: "In the last 6 months, have you purchased cheaper cigarettes than you can get from local stores for economic reasons?" Purchasing cigarettes from cheaper sources was defined as those who answered 'occasionally' and 'often' to that question, whereas not purchasing cigarettes from cheaper sources was defined as those who answered 'never'. Those who did not answer or reported unknown status were coded as missing.

\section{Independent variables}

Two groups of independent variables were included: sociodemographic characteristics and smoking intensity. Sociodemographic characteristics included gender, age, marital status, monthly household income, education, employment status and city of residence. Age was grouped into 18-24-years-old, 2539-years-old, 40-54-years-old and 55-years-old or older. Marital status was classified as married or living together, divorced or separated or widowed and single. Monthly household income was classified into four categories based on the cut-offs for urban areas from the 2010 China Statistics Yearbook $^{18}$ : low income ( $<1000$ Yuan, equal to US\$147 using the 2009 exchange rate of 6.8 Yuan per dollar ${ }^{18}$ ), middle income (1000-2999 Yuan, equal to US\$147-441) and high income (>3000 Yuan, equal to US\$441). Education was categorised as low education (less than high school), middle education (high school) and high education (more than high school). Employment status was classified as employed, unemployed and retired. Smoking intensity was categorised as light ( $\leq 10$ cigarettes per day (CPD), moderate (11-20 CPD) and heavy $(\geq 21$ CPD) smokers.

\section{Statistical analysis}

All analyses were conducted with STATA, V.12.0. Because of the longitudinal nature of the data, the general estimating equations $(\mathrm{GEE})^{19}{ }^{20}$ model was used to examine the significant factors associated with purchasing cigarettes from cheaper sources among current smokers. In the estimation, the GEE model was 
specified with a binomial distribution and logit link. We used quasi-likelihood under the independence model criterion (QIC) for model selection. We compared models with different correlation matrix structures (independent, autoregressive, exchangeable and unstructured) and chose the exchangeable working correlation matrix structure because it yielded the lowest QIC score. Adjusted ORs (AORs) and the corresponding 95\% CIs were computed to assess the strength of association. A twotailed $\mathrm{p}$ value of $<0.05$ was considered statistically significant.

\section{RESULTS}

\section{Sociodemographic characteristics and smoking intensity}

The sociodemographic characteristics of the study sample are reported in table 1 . Most current smokers were men (95.4\%), married or living together $(90.8 \%)$, aged $40-54$ years $(50.4 \%)$, of middle education (68.4\%) and employed (59.9\%). 16.0\% of current smokers were low income, and $46.2 \%$ and $37.8 \%$ were

Table 1 Sociodemographic characteristics and smoking intensity of respondents reporting current smoking in Waves 1-3 of the International Tobacco Control China Survey ( $\mathrm{N}=7980)$

\begin{tabular}{|c|c|c|}
\hline Characteristic & $\mathbf{n}$ & Per cent \\
\hline \multicolumn{3}{|l|}{ Gender } \\
\hline Men & 7610 & 95.4 \\
\hline Women & 370 & 4.6 \\
\hline \multicolumn{3}{|l|}{ Age (years) } \\
\hline $18-24$ & 55 & 0.7 \\
\hline $25-39$ & 1188 & 14.9 \\
\hline $40-54$ & 4024 & 50.4 \\
\hline $55+$ & 2713 & 34.0 \\
\hline \multicolumn{3}{|l|}{ Marital status } \\
\hline Married or living together & 7246 & 90.8 \\
\hline Divorced or separated or widowed & 466 & 5.8 \\
\hline Single & 268 & 3.4 \\
\hline \multicolumn{3}{|l|}{ Monthly household income } \\
\hline Low & 1273 & 16.0 \\
\hline Middle & 3687 & 46.2 \\
\hline High & 3020 & 37.8 \\
\hline \multicolumn{3}{|l|}{ Education } \\
\hline Low & 929 & 11.7 \\
\hline Middle & 5462 & 68.4 \\
\hline High & 1589 & 19.9 \\
\hline \multicolumn{3}{|l|}{ Employment status } \\
\hline Employed & 4779 & 59.9 \\
\hline Unemployed & 1012 & 12.7 \\
\hline Retired & 2189 & 27.4 \\
\hline \multicolumn{3}{|l|}{ City } \\
\hline Beijing & 1577 & 19.8 \\
\hline Shenyang & 990 & 12.4 \\
\hline Shanghai & 1673 & 21.0 \\
\hline Changsha & 1414 & 17.7 \\
\hline Guangzhou & 1139 & 14.3 \\
\hline Yinchuan & 1187 & 14.9 \\
\hline \multicolumn{3}{|l|}{ Smoking intensity (CPD) } \\
\hline Light $(0-10)$ & 2784 & 34.9 \\
\hline Moderate (11-20) & 3933 & 49.3 \\
\hline Heavy $(21+)$ & 1263 & 15.8 \\
\hline Total & 7980 & \\
\hline
\end{tabular}

middle income and high income, respectively. Nearly half were moderate smokers (49.3\%).

\section{Behaviour of purchasing cigarettes from cheaper sources and associated factors}

$15.6 \%$ of smokers reported purchasing cigarettes from cheaper sources during the last 6 months (see table 2). The GEE results showed that the associations between the behaviour of purchasing cigarettes from cheaper sources and age and income were statistically significant after controlling for other covariates. Smokers aged 18-24 years were more likely to purchase cigarettes from cheaper sources in the last 6 months than smokers aged 55 years and above $(\mathrm{AOR}=1.49,95 \% \mathrm{CI} 1.17$ to 3.92$)$.

Table 2 Percentage of smokers who recently purchased cigarettes from cheaper sources by characteristic and AORs from the general estimating equations model

\begin{tabular}{|c|c|c|c|}
\hline Characteristic & $\begin{array}{l}\text { Per cent } \\
\text { purchasing } \\
\text { cigarettes from } \\
\text { cheaper sources }\end{array}$ & AOR & $95 \% \mathrm{Cl}$ \\
\hline Total & 15.6 & & \\
\hline \multicolumn{4}{|l|}{ Gender } \\
\hline Men & 15.8 & Reference & \\
\hline Women & 12.2 & 0.68 & 0.44 to 1.05 \\
\hline \multicolumn{4}{|l|}{ Age (years) } \\
\hline $18-24$ & 23.6 & $1.49 *$ & 1.17 to 3.92 \\
\hline $25-39$ & 20.2 & 1.32 & 0.94 to 1.84 \\
\hline $40-54$ & 15.6 & 0.92 & 0.71 to 1.19 \\
\hline $55+$ & 13.6 & Reference & \\
\hline \multicolumn{4}{|l|}{ Marital status } \\
\hline Married or living together & 15.6 & Reference & \\
\hline $\begin{array}{l}\text { Divorced or separated or } \\
\text { windowed }\end{array}$ & 17.2 & 1.10 & 0.78 to 1.54 \\
\hline Single & 13.8 & 0.70 & 0.43 to 1.16 \\
\hline \multicolumn{4}{|l|}{ Monthly household income } \\
\hline Low & 26.2 & $2.93^{*}$ & 2.27 to 3.79 \\
\hline Middle & 17.0 & $1.73^{*}$ & 1.39 to 2.15 \\
\hline High & 9.5 & Reference & \\
\hline \multicolumn{4}{|l|}{ Education } \\
\hline Low & 17.2 & 0.90 & 0.64 to 1.27 \\
\hline Middle & 16.1 & 0.99 & 0.76 to 1.29 \\
\hline High & 13.0 & Reference & \\
\hline \multicolumn{4}{|l|}{ Employment status } \\
\hline Employed & 14.9 & Reference & \\
\hline Unemployed & 24.7 & 1.21 & 0.94 to 1.56 \\
\hline Retired & 13.0 & 0.84 & 0.63 to 1.12 \\
\hline \multicolumn{4}{|l|}{ City } \\
\hline Beijing & 11.1 & Reference & \\
\hline Shenyang & 19.3 & 1.29 & 0.88 to 1.90 \\
\hline Shanghai & 10.4 & 0.80 & 0.55 to 1.16 \\
\hline Changsha & 15.1 & 1.00 & 0.69 to 1.46 \\
\hline Guangzhou & 13.6 & 1.03 & 0.69 to 1.54 \\
\hline Yinchuan & 28.7 & $2.22^{*}$ & 1.53 to 3.23 \\
\hline \multicolumn{4}{|l|}{ Smoking intensity (CPD) } \\
\hline Light (0-10 CPD) & 14.7 & Reference & \\
\hline Moderate (11-20 CPD) & 15.8 & 0.96 & 0.78 to 1.19 \\
\hline Heavy (21+ CPD) & 17.4 & 0.91 & 0.68 to 1.22 \\
\hline
\end{tabular}


Low-income smokers were more than twice as likely to purchase cigarettes from cheaper sources as high-income smokers $(\mathrm{AOR}=2.93$, 95\% CI 2.27 to 3.79$)$. This association was slightly smaller among middle-income smokers. Compared with Beijing smokers, smokers in Yinchuan were more likely to purchase cigarettes from cheaper sources. There was no statistically significant relationship between smoking intensity and purchasing cigarettes from cheaper sources.

\section{DISCUSSION}

The results of this study indicate that in China, low-income smokers were 2.93 times as likely as high-income smokers, and middle-income smokers were 1.73 times as likely as highincome smokers to purchase cigarettes from cheaper sources. These findings are consistent with most studies showing that low-income smokers are more likely to use price-minimising strategies to lower their cigarette expenditures than high-income smokers, ${ }^{13} 21$ although one recent study reported that lowincome US smokers were less likely to use price-minimising strategies. $^{22}$

Consistent with a previous study that showed young adults in the USA were more likely to use price-minimising strategies than older adults, ${ }^{13}$ our study found that one such behaviour in China is purchasing cigarettes from cheaper sources. Young adults have been regarded as an important target by the tobacco industry for many years. ${ }^{23}$ Limits on the availability of cigarettes from cheaper sources may encourage more young adult smokers to quit or cut down on smoking.

Our results are consistent, albeit not statistically significant, with two US studies which reported that heavy smokers $(\geq 15$ CPD) were more likely than light smokers $(<15$ CPD) to buy cigarettes from less expensive places. ${ }^{13}{ }^{22}$ Because we used different cut-offs for intensity (to be consistent with other studies of ITC China Survey data), it is not possible to compare our results directly with results from these two studies. More research is needed to further examine the relationship between smoking intensity and the purchasing of cigarettes from cheaper sources.

The proportion of smokers purchasing cigarettes from cheaper sources found in this study $(15.6 \%)$ is lower than the proportion reported in three studies conducted in the USA, which reported proportions of 34-61.1\%. ${ }^{10} 1113$ This may be because the three US studies included additional measures of price-minimising strategies, such as buying cigarettes from Indian reservations, other states or other countries and using coupons or promotions.

In addition, our study found that smokers in Yinchuan were more likely to purchase cigarettes from cheaper sources than smokers in Beijing. This may be because Yinchuan is the least developed of the cities included in the study and has lowest per capita annual household income. ${ }^{18}$ It is also possible that access to cigarettes from cheaper sources was easier in Yinchuan.

Taxation is often used to increase cigarette prices to reduce consumption. ${ }^{24-26}$ To date, the goal of increasing prices by raising cigarette taxes in China has not been achieved. In May 2009 , in order to fulfil its obligation to the Framework Convention on Tobacco Control, China raised cigarette taxes at the producer level. ${ }^{26}$ However, studies based on both observational and survey data found that the cigarette retail prices did not change after this tax adjustment, and the tax adjustment was just a redistribution between producer prices and wholesale prices. $^{27} 28$ Moreover, survey data showed that cigarette nominal retail prices in China actually decreased from 2007 to $2010 .{ }^{27}$ As a result, the 2009 increase in the tax on cigarettes in
China failed as a public health policy because that tax increase did not result in any increase in cigarette retail prices. Our study suggests that if China were to implement a tax increase that increases cigarette retail prices, reduction in consumption may still not be achieved due to consumers purchasing cigarettes from cheaper sources in order to minimise the prices they pay. A study conducted in the USA found that smokers who reported buying cigarettes from cheaper sources were less likely to intend to quit smoking, ${ }^{11}$ which suggests that the availability of cigarettes from cheaper sources may weaken intentions to quit. Therefore, making cigarettes from cheaper sources less available could be an effective way to reduce cigarette consumption in China. Without access to cigarettes from cheaper sources, when cigarette prices increase, smokers in China would be faced with fewer substitution options and might instead consider quitting or reducing cigarette consumption.

It is also possible that smokers facing higher prices might switch to cheap brands of cigarettes. Cheap cigarettes are not equivalent to cigarettes from cheaper sources, which is the main focus of this study. There has been no study examining the purchase of cigarettes from cheaper sources or its relationship with the behaviour of purchasing cheaper cigarettes among smokers in China. A subanalysis of our data showed that 43.1\%, 33.4\% and $23.5 \%$ of smokers in our study sample purchased cheap brands of cigarettes (less than 5 Yuan per pack), median-priced brands (5-40 Yuan per pack) and expensive brands (over 40 Yuan per pack), respectively. Among smokers who purchased cheap brands of cigarettes, $20.5 \%$ of them bought their cigarettes from cheaper sources. This percentage was only $11.0 \%$ and $16.4 \%$ for smokers who purchased expensive brands and median-priced brands, respectively. Therefore, this study provides evidence that some smokers who purchased cheap or more expensive brands of cigarettes reported purchasing cigarettes from cheaper sources. Hence, the availability of cigarettes from cheaper sources results in additional challenges for tobacco control in China beyond the availability of cheap cigarettes.

There were several limitations to this study. First, we used self-reported data. Due to distrust of unfamiliar people, smokers in China might not be willing to report buying cigarettes from cheaper sources in a face-to-face survey with an unknown interviewer, which may lead to under-reporting of this behaviour. Also, self-reported information may be subject to recall bias. Second, the wording of the ITC China Survey question used to construct the dependent variable may lead more low-income smokers compared with high-income smokers to answer in the affirmative since 'economic reasons' is in the question. However, a previous study by $\mathrm{Li}$ et $a l^{16}$ used an objective measure-the price of cigarettes paid by smokers-to examine the correlates of purchasing cheaper cigarettes in China. Their finding that low-income smokers were more likely than highincome smokers to purchase cheaper cigarettes is consistent with our finding that lower income smokers were more likely than high-income smokers to purchase cigarettes from cheaper sources. Nevertheless, future study with a preferred survey question (eg, "Have you purchased cigarettes from other sources because they were cheaper?") would be useful. Third, the ITC China Survey did not ask separate questions about specific cheaper sources. Therefore, we cannot determine what proportion of the smokers, who purchased cigarettes from cheaper sources, purchased via internet versus discount cigarettes. Future research is needed in this area. Fourth, this study only included smokers. Those smokers who did not access cheaper sources to purchase cigarettes might quit smoking. Therefore, there may be 
selection bias in the estimation because continuing smokers might be those who were more likely to find and purchase cigarettes from cheaper sources. Finally, while the ITC China Survey draws its samples from urban cities (which account for less than $10 \%$ of the total population ${ }^{18}$ ), $54.3 \%$ of the Chinese population live in a rural area, so these findings may not be generalisable to the national level.

In summary, our study found that younger and low-income smokers are more likely than older and high-income smokers to purchase cigarettes from cheaper sources in China. Tobacco control policies that ultimately reduce the availability of cigarettes from cheaper sources could have great potential for reducing cigarette consumption, especially among young and low-income smokers in China.

\section{What this article adds}

- This article shows that young and low-income smokers are more likely than older and high-income smokers to purchase cigarettes from cheaper sources in China.

- Tobacco control measures need to be implemented to reduce the availability of cigarettes from cheaper sources, which could have an impact on reducing cigarette consumption among young and low-income smokers in China.

Acknowledgements We thank the Chinese Center for Disease Control and Prevention and the local CDC representatives in each city for their collection of data, and Prof Frank Chaloupka at the University of Illinois at Chicago, Richard S. Gallagher and members of the University of California, San Francisco Tobacco Center's Writer's Task Force for their helpful comments and suggestions.

Contributors GF and YJ conceptualised the study, obtained funding and collected data. TY, JH, WM, HS, MO and ZM participated in the data analysis and interpretation of the results. All drafts were written by TY and commented on by all authors. All authors read and approved the final manuscript.

Funding The ITC China Project was supported by grants from the US National Cancer Institute (R01 CA125116 and P01 CA138389), the Roswell Park Transdisciplinary Tobacco Use Research Center (P50 CA111236), the Canadian Institutes of Health Research (57897, 79551 and 115016) and the Chinese Center for Disease Control and Prevention. Additional support was provided by the US National Institutes of Health Fogarty International Center (Grant R01 TW05938), the US National Cancer Institute (Grant CA-113710) and the University of California, San Francisco Dorothy Pechman Rice Postdoctoral Fellowship. Geoffrey T Fong was supported by a Senior Investigator Award from the Ontario Institute for Cancer Research and by a Prevention Scientist Award from the Canadian Cancer Society Research Institute.

Competing interests GTF was supported by a Senior Investigator Award from the Ontario Institute for Cancer Research and by a Prevention Scientist Award from the Canadian Cancer Society Research Institute.

Patient consent Obtained.

Ethics approval The ITC China Survey was conducted with the approval of China CDC Ethical Review Committee and the Office of Research Ethics Committee at the University of Waterloo.

Provenance and peer review Not commissioned; externally peer reviewed.

\section{REFERENCES}

1 Chinese Center for Disease Control and Prevention. Global Adult Tobacco Survey (GATS) Fact Sheet China. 2010. http://www.cdc.gov/tobacco/global/gats/countries/ wpr/fact_sheets/china/2010/index.htm (accessed 25 Mar 2011).

2 Yang GH, Hu AG. eds. Tobacco Control and the Future of China. Beijing, China: The Economic Daily Press, 2011:109-16

3 Yunnan's tobacco boom: Poisonous gift. The Economist Jan 28th 2012. http://www. economist.com/node/21543594 (accessed 12 Jun 2012).

4 World Health Organization. Towards a tobacco-free China. Geneva, Switzerland: World Health Organization, 2007. http://www.wpro.who.int/china/sites/tfi/ (accessed 15 Aug 2007).

5 Murray CJL, Lopez AD. Alternative projections of mortality and disability by cause 1990-2020: global burden of disease study. Lancet 1997;349:1498-504.

6 Yang L, Sung HY, Mao ZZ, et al. Economic costs attributable to smoking in China: update and an 8-year comparison, 2000-2008. Tob Control 2011;20:266-72.

7 Chaloupka FJ. Macro-social influences: the effects of prices and tobacco contro policies on the demand for tobacco products. Nicotine Tob Res 1999;(Suppl 1): S105-9.

8 Warren CW, Erguder T, Lee J, et al. Effect of policy changes on cigarette sales: the case of Turkey. Eur J Public Health 2012;5:712-6.

9 Chaloupka FJ, Yurekli A, Fong GT. Tobacco taxes as a tobacco control strategy. Tob Control 2012;21:172-80

10 Hyland A, Bauer JE, Li Q, et al. Higher cigarette prices influence cigarette purchase patterns. Tob Control 2005;14:86-92.

11 White VM, Gilpin EA, White MM, et al. How do smokers control their cigarette expenditures? Nicotine Tob Res 2005;7:625-35.

12 Hrywna M, Delnevo CD, Staniewska D. Prevalence and correlates of internet cigarette purchasing among adult smokers in New Jersey. Tobacco Control 2004:13:296-300.

13 Choi K, Hennrikus D, Forster J, et al. Use of price-minimizing strategies by smokers and their effects on subsequent smoking behaviors. Nicotine Tob Res 2012;14:864-70

14 Tong E, Tao M, Xue Q, et al. China's tobacco industry and the World Trade Organization. In: Hu T, ed. Tobacco Control Policy Analysis in China: Economics and Health. Singapore: World Scientific, 2007:211-44.

15 China National Tobacco Company. China Tobacco Yearbook. Beijing: China Economic Publishing House, 2000-2009.

16 Li Q, Hyland A, Fong GT, et al. Use of less expensive cigarettes in six cities in China: findings from the International Tobacco Control (ITC) China Survey. Tob Control 2010;19(Suppl 2):i63-8.

17 Wu CB, Thompson ME, Fong GT, et al. Methods of the International Tobacco Control (ITC) China Survey. Tob Control 2010;19(Suppl 2):i1-5.

18 National Bureau of Statistics of China. China Statistical Yearbook. China Statistica Press, 2010.

19 Hardin J, Hilbe J. Generalized estimating equations. London: Chapman and Hall/ CRC, 2003. ISBN:978-1-58488-307-4.

20 Diggle PJ, Heagerty $P$, Liang KY, et al. Analysis of longitudinal data. Oxford Statistical Science Series, 2002. ISBN:978-0-19-852484-7.

21 Cummings KM, Hyland $A$, Lewit $E$, et al. Use of discount cigarettes by smokers in 20 communities in the United States, 1988-1993. Tob Control 1997;6:S25-30.

22 Pesko MF, Kruger J, Hyland A. Cigarette price minimization strategies used by adults. Am J Public Health 2012;102:e19-21.

23 Ling PM, Glantz SA. Why and how the tobacco industry sells cigarettes to young adults: evidence from industry documents. Am J Public Health 2002;92:908-16.

24 Hu TW, Mao Z, Shi J, et al. The role of taxation in tobacco control and its potential economic impact in China. Tob Control 2010;19:58-64.

25 Chaloupka F. How effective are taxes in reducing tobacco consumption. In: The social cost of smoking. Lausanne, Switzerland, 1998. http://tigger.uic.edu/ fjcl Presentations/Papers/taxes_consump_rev.pdf (accessed 05 Sep 2012).

26 Chen J. Ministry of industry and information technology stated that China earnestly implements FCTC. Southern Metropolis Daily 28 January 2011 (accessed 12 Aug 2012)

27 Li Q, Hu TW, Mao Z, et al. When a tax increase fails as a tobacco control policy: the ITC China project evaluation of the 2009 cigarette tax increase in China. Tob Control 2012:21:381-90.

$28 \mathrm{Hu}$ TW, Mao Z, Shi J. Recent tobacco tax rate adjustment and its potential impact on tobacco control in China. Tob Control 2010;19:80-2. 